\title{
MANUAL DE ESTADÍSTICA PARA PSICOLOGÍA VOL. 2. ESTADÍSTICA INFERENCIAL*
}

\author{
Reseña a cargo de la Prof. Dra. Reina Coral García Pérez
}

El libro de texto del Prof. Daniel Sucazes (2010) Manual de Estadística para Psicólogos, Estadística Inferencial, segundo tomo, es la continuación del primer manual del mismo nombre y completa así, un recurso invalorable para estudiantes, profesionales y académicos que desarrollan investigaciones científicas o buscan contar con instrumentos claros para la lectura y comprensión de las mismas.

El autor, en este trabajo, presenta de manera detallada los aspectos más relevantes de la enseñanza de la estadística inferencial; lo que lo hace muy útil como manual de curso. Presenta cada uno de los temas de manera ordenada y clara, con el fin de facilitar el aprendizaje de la estadística como recurso para la comprobación de hipótesis. Se pone de manifiesto en la organización del libro la experiencia de 25 años de docencia del autor a nivel universitario.

El libro está organizado en nueve capítulos (siguiendo la numeración desde el Tomo I) que incluyen una revisión completa de las principales herramientas de estadística para realizar prueba de hipótesis. En cada uno parte de una descripción de objetivos según el contenido y especifica además, las competencias que el estudiante adquirirá en el aprendizaje. Se incluyen, una gran variedad de ejemplos y ejercicios prácticos, que facilitan el acceso a conceptos matemáticos complejos en forma sencilla y amena.

En el primer capítulo, Introducción a la Teoría del Muestreo (Capítulo 5), el autor explica y sustenta la importancia de la Estadística como herramienta de apoyo a la investigación científica. En detalle, expone los conceptos de muestra, población, parámetro, técnicas de construcción de estimadores de los parámetros más usados en la descripción de poblaciones y muestro aleatorio simple para poblaciones infinitas.

El Capítulo 6 presenta una definición y distinción entre hipótesis de trabajo e hipótesis estadística y determina la utilidad de las hipótesis estadísticas como condición o vía para la comprobación de hipótesis, nivel de estimación y potencia. Explicando en la última parte, el procedimiento general para realizar docimasia de hipótesis, cómo elegir el nivel de significación, así como, los supuestos que deben cumplirse en este proceso.

Desde el capítulo 7 al 12, se desarrollan técnicas estadísticas para efectuar dócimas específicas con métodos paramétricos. Estos apartados ofrecen la posibilidad de reconocer y emplear distintos recursos según las características de la/s hipótesis planteada/s y de los datos a los que accede. Incluye en el capítulo 7, dócimas sobre el valor del parámetro en poblaciones con distribución de Bernoulli. En el capítulo 8 dócimas sobre la bondad de ajuste a un modelo. Capítulo 9, dócimas sobre el valor de la media. Capítulo 10, dócimas sobre el valor de la varianza. En el № 11, dócimas sobre la igualdad de la medida de dos o más poblaciones y en el 12 , dócimas sobre parámetros de poblaciones bidimensionales.

*NE: Este libro ha recibido el Premio Primitivo Techera a la Producción Académica, 2008. 
Por último, en el Capítulo 13, se exponen los métodos no paramétricos más utilizados, cuando no se cumplen las condiciones necesarias para utilizar los métodos paramétricos en docimasia de hipótesis.

Esta obra si bien ha sido creada especialmente como manual de curso de grado, puede resultar de utilidad para profesionales y académicos como libro de consulta, ya que prepara para una mejor comprensión de las comunicaciones de otros investigadores y para aquellos que trabajan en el ámbito de la investigación científica.

Sucazes, Daniel (2009). Manual de Estadística para Psicología. Vol. 2: Estadística Inferencial Montevideo: Prensa Médica Latinoamericana 